\title{
Observing Groups As Seen from Both Sides of the Looking Glass
}

\author{
Peter A. Martin, Muriel Tornga, \\ James F. McGloin, Jr., and Steven Boles
}

\section{INTRODUCTION - THE SETTING}

Clinical training centers have increasingly utilized direct observation experiences in the teaching of psychotherapy. Such practice is especially common in the fields of group and family therapy. Much of the literature on such practice has dealt with the effects of observers on the process of therapy. In contrast, very little has been published on the dynamics of the observing group itself or on the effects of the therapy process upon the observers. This paper presents contributions along these lines from (1) the senior author, on the basis of 25 years of teaching psychotherapy by demonstration to observing groups at university training centers; (2) the junior authors, on the basis of several years of participation in observing groups at the University of Michigan, including a current group that began in November 1975; and (3) several therapists-in-training, ${ }^{1}$ on the basis of their participation as cotherapists or observers in the current groups at Michigan.

This observation group experience has developed within the context of a Marital and Family Therapy Clinic in the Outpatient Department of Psychiatry, University of Michigan, where the senior

Peter A. Martin, MD, is Clinical Professor of Psychiatry, University of Michigan and Wayne State University Medical Schools; Muriel Tornga, ACSW, is Lecturer in Psychiatry, University of Michigan Medical School and Executive Director of the Marital and Family Therapy Clinic, Outpatient Department of Psychiatry; James F. MCGloin, Jr., ACSW, the former Executive Director of the Marital and Family Therapy Clinic in the University of Michigan, is presently a doctoral student at the University of Wisconsin at Madison; and Steve Boles, MA, is a social worker in private practice in Ann Arbor, Michigan, and Toledo, Ohio. Requests for reprints may be addressed to Muriel Tornga, ACSW, Uiversity of Michigan, Psychiatry Outpatient Department, Riverview Building, Ann Arbor, Michigan 48104.

1. Raylene Fenton, MSW; Thomas Kozak, MA; Michael Liepman, MD; and Ann Snyder, MD. 
author conducts a weekly seminar on marital therapy. Available to residents in training, student social workers, psychology interns, staff members, and interested community professionals (ranging from counselors to psychiatrists), the seminar provides an opportunity to experience, through both clinical supervision and live observation, the range of modalities utilized in the treatment of marital dysfunction. A major portion of this seminar's activity centers around a married couples group, conducted by a male (senior author)/female cotherapist couple, which is observed directly by approximately 10 seminar members through a one-way mirror. Unplanned for but predictable was the formation of an intensely involved, close-knit observation group with its own group process and dynamics.

In the current group, the senior author has occupied a position as therapist of the group of married couples who are being observed and as the teacher of the observing group, as well as teacher and colleague of the cotherapist. Although his effort is to maintain the primacy of the educational function during the observing group's post-therapy discussions, the senior author is at times unavoidably thrust into a psychotherapeutic position with the observing group and with the cotherapist. The junior authors, as members of the current observing group, have both observed the group therapy sessions and then participated immediately afterwards in their own group discussion sessions. They and the other contributors listed in footnote 1 , as well as several other students, have experienced in this training process the pains and pleasures of personal growth through learning, and learning through personal growth. The two have proven to be painfully inseparable.

The use of the one-way mirror and the differing experiences of the authors on each side of the mirror determined the title of this paper. These experiences are sometimes nearly as wondrous as those depicted by Lewis Carroll during Alice's visit to Wonderland. That the metaphor was valid and that the Alice-in-Wonderland milieu was also experienced by the therapy group were discovered after the first draft of this paper was written. The cotherapist, a resident in training, was due to leave. The therapy group handled their loss of her by turning her final session into a party and giving her the gift of a print and a card with a quote from "Through the Looking Glass." Individual growth and development had been the theme of the therapy group from its inception. The group had seen hope for themselves through the cotherapist's growth and development, and they now wished her well in her continuing progress. It was a moving session in which they transcended and escaped from their own characterological prisons through identification with the departing cotherapist. The lines they 
chose for the farewell card were those Alice uses when she laughs and says to the Queen, "There is no use trying. One can't believe in impossible things," to which the Queen replies, "When I was your age, I always did it for one-half hour a day. Why sometimes I believed as many as six impossible things before breakfast." The therapy group had jelled around first dreaming and then achieving the impossible dream-continuous growth and development within the group setting.

This wondrous response of the therapy group was met with an equally wondrous response in the observing group as they later feted and lauded the departing cotherapist with a party of their own and the gift of recognizing her personal growth through her experience.

\section{THE VIEW FROM THE TEACHING THERAPIST'S SIDE OF THE LOOKING GLASS}

\section{Effect of Observing Group upon Therapy Group}

One of the factors that the teaching therapist must take into account is the effect of observers on the process of group therapy. Both he and the therapy group are at times aware of the presence of observers on the other side of the mirror. The disadvantages are obvious and have been reported in the literature (Bloom and Dobie, 1969). For example, the presence of the observing group can be used as a source of resistance by the therapy group. This has to be dealt with, as does any type of resistance. However, the more valid the reality factors are, the more difficult it is to work through such resistance. The literature recognizes that therapy can be inhibited by such factors as observers, recording apparatus, cotherapists, and violations of confidentiality and trust (Berne, 1966; Goforth, Mowatt, \& Clarke, 1966). Other authors (Bloom and Dobie, 1969; Kadushin, 1967; Powdermaker \& Frank, 1953) contradict these observations, and their research leads to the conclusion that there need be no inhibition of psychotherapy; some (Powdermaker \& Frank), indeed, suggest that there may even be facilitation of spontaneity in the presence of observers. It has been our experience that some narcissistic patients do bask in the light of an interested audience, experiencing the situation of being observed as one in which their importance is increased. We have also found that most patients work effectively under observation while being relatively indifferent to the fact of being observed. It is surprising how quickly and how often the therapy group is oblivious to the observing group. At the same time, we have noted 
that work under these conditions-or even in unobserved group therapy-is especially difficult for those individuals whose dynamics necessitate an intimate one-to-one relationship, such as symbiotically oriented or paranoid individuals (Martin, 1976). Hence, a principle needs to be stated: There is no magic in any one technique. Each has advantages and disadvantages. The disadvantages with each individual have to be recognized and-if they become a source of resistance-must be dealt with, if possible. However, with a few individuals, a disadvantage will become an insurmountable obstacle. In these cases, other choices should be given or such persons will either drop out of treatment or not enter into it even if they remain in the group setting.

Another effect of the observing group's presence is to split the responsibilities of the senior therapist ${ }^{2}$ so that he is simultaneously a teacher to the observing group and a therapist to the therapy group. At times he is aware of choosing an approach to the therapy group that fits the particular educational needs of the observing group. More frequently, as he becomes intensely involved in the therapeutic group process, he will disregard his role as teacher. One such example occurred when the therapist was so involved with a crisis situation in the therapy group that he ran far past the scheduled time. When the observing group came in, they were angry that he had not been considerate of them and had used up "their" time. The group process in the therapy group and the group process in the observing group may sometimes be in opposition, and at these times the therapist must give priority to the therapy group.

\section{Response of Observing Group to Therapy Process}

These observations lead to another experience that has been reported in the literature. As the therapists are joined by the observers for discussion of what transpired during the session, they are confronted with a highly charged emotional group. As passive observers, unable to enter into the action of the therapeutic group to relieve their inner tensions, the observers tend to be more distraught than the cotherapists themselves. The contrast is often marked. The cotherapists may be quite satisfied with what has transpired during the group session, while the observing group is dissatisfied: "The group may attack the

2. The term senior therapist is used because the cotherapist, as often happens in educational institutions, is a trainee more closely allied in position to the observing group than to the senior teaching therapist. 
therapist's techniques as his supervisors, they may [one-sidedly] identify with the patient, or with the therapist; or they may reject the therapist entirely" (Wolman, 1970).

Often observers will react intensely to the therapists' technique, confronting them accusingly with "Why did you do that?" or "Why didn't you do this?" and seeing only one "right" response to the given situation. Such responses may be aggravated by the senior author's cautions against attributing magical qualities to specific techniques or interpretations as if there were only one "right" thing to do in any instance. He considers it important to observe that whatever one does will have advantages and disadvantages. He stresses continuous observation of patients' interactions over a period of time to recognize individual styles of defense. In addition, he emphasizes that the "correct" interpretation may be ineffective with some patients, and that an incorrect interpretation may be used advantageously by others. Hence, the approach emphasized is one of "wait-listen-and-see" before coming to final conclusions about technique and what is the "right" or "wrong" thing to do or say. This approach to psychotherapy is often frustrating to an observing group when they are overidentified with the patient. This "wait-listen-and-see" approach is also contrary to that literature that stresses that the observers "are quite perceptive and frequently point out the 'blind spots' of the therapists" (Kritzer \& Phillips, 1966). We don't find observers to be as broadly perceptive as they think they are. The observing group experience helps them to learn this painful truth. Even when the observers are correct in the content of their perceptions, it is important to recognize that other dynamics (group or individual) are also involved in their stressing of therapist blind spots, "especially in the light of the intensity and tenaciousness with which one often finds these views to be held" (Wolman). In one such example, as an observer criticized a therapists's approach to a particularly resistant individual as being too direct, he laughingly admitted that he could see himself in the resisting patient and found himself speaking against having to change himself.

The same principle of listening applies in the observers' relation to the therapists. The observers, instead of rushing to show the defect in a therapist's response, might more appropriately ask themselves, "How is the therapist right in his response? What is intended here, how does it relate to the patient's material, or to the therapeutic situation as a whole at this moment, and what are the likely advantages and disadvantages in this response for this patient (and for the others in the group) now and in the long run?" As the observers learn to recognize, contain, and consider their own automatic, idiosyncratic (transference and countertransference) reactions, and to listen to patients' material and therapists' 
responses in the manner indicated above, they move toward an increased capacity for a planful and therapeutic use of themselves in the clinical situation.

As Ekstein and Wallerstein indicate in their classic text, The Teaching and Learning of Psychotherapy (1972), the capacity to work in terms of the technical skill problems posed by the patient's material is "a rather late achievement in the training process of the young therapist" (p. 173). At first, he must learn that "at times he acts and responds within the psychotherapeutic [or observational] situation in ways that are determined, not by the objectively demonstrated needs of the patient, but by characteristic, automatic and [sometimes] inappropriate patterns within himself. These he discovers to be his learning problems" (p. 158). Then "as the therapist becomes more fully aware of his own automatic response tendencies in the therapeutic situation, he will also become increasingly able to modify these responses in terms of the objectively determined needs of the patient - to acquire, that is, increased therapeutic skill" (p. 174). As this shift in professional functioning occurs, the "learning problems" are maturing into "technical-skill" problems. Technical and theoretical considerations now emerge more regularly as the student therapist focuses on problems involving which of various responses, if any, to make to a patient's material at any given moment.

\section{Handling of Observers' Responses by Teaching Therapist}

As suggested above, there are many possible reasons for the intense negative reactions and one-sided identifications that often occur in the observing group. Some emanate from individual transference reactions and others from the observing group process. In handling these reactions, the senior therapist is in a sensitive position with the observing group. The contract between himself and the observers is educational rather than psychotherapeutic. Yet, the emotional needs of the particular observers (and of the junior cotherapist) will affect their involvement in the whole process. The senior therapist finds himself in the same bind that occurs in individual supervision of psychotherapy, but multiplied several times. Though his role in supervising psychotherapy is that of a teacher, the nature of the psychotherapeutic relationship highlights transference reactions and psychopathologic reactions in the trainees. The supervisor-teacher may recognize and utilize such reactions for educational purposes and for the growth and development of the trainee, or he may choose to leave such material untouched so as not to upset the trainee. Jugments of this sort become 
more complex in a group situation. It is often simpler to indicate countertransference reactions in a one-to-one supervisory situation than in a group setting, where exposure of individual problems before one's peers may be an exceedingly painful experience. In the observing situation, the transference reactions directed towards the therapistteacher by the observers can be as intense as those emanating from the treatment group itself. Utilization of the vicissitudes of the supervisory or the observing situation provides unique opportunities for the trainees, enabling them to move from a position of dependence on the teacher or supervisor to one of independence from him. Dealing openly with the emotional issues between teacher or supervisor and trainee contributes greatly to the achievement of this goal. Yet, in university training centers a therapeutic contract with observers or supervisees is seldom present. Hence, the teacher or supervisor must maintain the primacy of the educational function and, if possible, prevent the development of intense transference-countertransference interactions between himself and the trainees that might disrupt the educational process.

In the absence of a therapeutic contract with the observing group, the senior therapist sometimes faces a difficult dilemma. At times, he finds himself unavoidably thrust into a therapeutic position with the observing group. Personal interpretations must be ignored and loss of therapeutic benefit for the observers must be accepted in order to protect the needed defense mechanisms of an individual member of the group. Individual homeostasis is the decisive factor. One method of handling such a dilemma in the observing situation is to avoid personal interpretations and to utilize group process interpretations instead. Emphasis is thus given to what happens to the interaction as a whole between the observing group and the senior therapist. This approach, although incapable of resolving severe, idiosyncratic reactions of a trainee, draws upon special advantages of groups and teaches group process by involving the observing group itself.

The senior author is not implying that he has always been successful in steering a safe course through these troubled waters. Under these circumstances, the teaching and learning process can and occasionally has become overly painful. If the observing group cannot be carefully selected, one difficulty is the wide disparity in levels of training and insight among the observing group members. Also, there is no substitute for time in developing trust within the observing group. The degree of trust depends not only on the personalities of the observers but also on the experience of direct interaction with each other through time. In the first phase of the observing group, when there is insufficient trust in the group, the teacher-therapist may choose 
to accept dropouts from the observing group rather than to expose an individual's psychodynamics. In such cases, as suggested above, a true dilemma exists. Protecting an individual from painful exposure forgoes opportunities for learning and growth. Yet exposing the individual's dynamics within the group may be extremely painful for him and may deprive him of needed mechanisms of defense. The teacher-therapist must keep in mind the differences between the observing group and the therapy group. The members of the therapy group, although exposed to similar traumas, come as patients asking for therapeutic help. Also, the other members of the therapy group are strangers they may never see outside of the group meetings. In contrast, members of the observing group come for educational purposes, and their group is composed of individuals who may work together daily and whose careers may run parallel for years.

Problems deriving from the split between educational and therapeutic functions can perhaps be mitigated by forming a therapeutic contract with the observing group. Thus, when their turn came for discussion following the couples group, the observers would be understood to be a therapeutic as well as an educational group, and one aspect could be used to enhance the other. Therapy groups of trainees are not uncommon in university training centers. In other settings, supervisory groups with a therapeutic contract have already been used regularly for clinical training. Such groups are based on the recognition that "techniques for teaching psychotherapy need to involve the student not only intellectually, but emotionally as well;" and also that "effective learning involves change and requires an emotional experience in which the student can make some modification in himself" (Kritzer \& Phillips).

\section{Response of Junior Cotherapist to Senior Therapist}

The relationship between the senior therapist and the junior cotherapist is a difficult one for the cotherapist. It, too, is clearly a highly charged emotional situation. Paradoxically, it encompasses a student and a therapist role at the same time. Most of what has already been said about the reactions of the observers also applies to those of the junior therapist. Competitiveness, a desire to look good to the peer group, one's sexual identification, and feelings of insecurity in the role of therapist contribute to anxieties in the first phase of therapy. Especially at this time, the junior therapist may react to the senior 
therapist's divided loyalties between the therapy group and the observing group and may feel that insufficient attention is being directed toward the cotherapy relationship itself. The continued presence of either patients or observers leaves little private time for the cotherapists (unless they structure it for some other time); hence, all relationship issues tend to be worked out in front of others. When the definition of the cotherapy relationship has not been adequately worked out, emotional needs and problems surface easily.

It is interesting that, in the opening phase of the group therapy, observations about the junior therapist coincide with conclusions drawn by Krasner, Feldman, Liff, Mermelstein, and Aronson (1964) about "observers" in psychotherapy groups. They reported that "the direct 'sitting-in' of trainees in psychotherapy groups on a regular basis fosters the development of unexpected and intense transferencecountertransference relationships between therapist and observer." They concluded that this was "unlike any other training experience, related perhaps to a continuum of degrees of remoteness between the trainer and the trainee." Their conclusion holds true for the observing group as well as for the junior therapist: "The observational experience not only induces more manifest transference on the part of the observers but also sets up transferential feelings from the trainer to the trainee by the very nature of being under observation, a situation which classroom instructors and supervisors do not have in their work" ( $p$. 217).

The complexities of status and sex role issues in cotherapy with marital partners have been recognized in the literature (Rice \& Rice, 1975). Therapist status differences and sex role prescribed behavior are easily perceived by patients. As greater cotherapist status equality and more flexible role behavior are achieved, they enhance treatment effectiveness. Another study of therapist experience and style in cotherapy revealed that there is a "point of diminishing returns" in cotherapy satisfaction with increasing numbers of couples seen (Rice, Fey, \& Kepecs, 1975).

Despite these difficulties, if the junior cotherapist can handle the first phase, the group experience in time becomes an excellent source of knowledge of self and of therapy skills and techniques. It can be both personally and educationally fulfilling. The teaching therapist must take the responsibility for helping the cotherapist trainee achieve these goals. A developmental process takes place as the cotherapist moves from observer to participant and then becomes a full-fledged member of the therapy team and a uniquely differentiated therapist self. 


\section{THE VIEW FROM THE OBSERVING GROUP SIDE OF THE LOOKING GLASS}

\section{As Seen by Regular Attenders}

The mutual experiencing of intense emotions in the observing situation hastens the formation of a family culture. First signs of culture formation in the observing group were the evolution of responsibility functions. In a brief period, several tasks were established which particular individuals chose to assume. One participant prepared the group room, drew the curtains, adjusted and controlled the audioequipment, and monitored the temperature of the observation room. Another kept group process notes, informed new participants of the therapy group's background, updated those who had been absent, controlled the traffic at the door of the observer room, and answered any phone calls interrupting the sessions. This individual also had administrative responsibilities to the seminar and had evaluated, selected, and prepared all of the couples for the therapy group. This combination of tasks led to the members' referring to his replacement in the group, a woman, as "Mom." Although this was never stated directly to him, it appeared to be the group's feeling in relation to these functions, since after his loss it was expressed to his successor. It was obvious that once this pattern was established, the group grew to rely on and expect such performances, and would comment on any disruption owing to absence, negligence, or loss with anxiety, humor, criticism, or statements such as "We missed you last time," and so on. Pressure was thus placed almost immediately on the female replacement to become "Old Mom," and when she seemed to deviate from the group's expectations, she was openly reminded of her responsibility to replace the lost "Mom" and help ease the unresolved feelings of loss. This new relationship is still being worked out in that the group has not come to terms fully with the loss of "Old Mom" (a warm, hard-working, maternal person), accepted "New Mom," and achieved a new balance of responsibilities and realistic expectations.

Simple patterns of group process can also be seen in the "pecking order" established in relation to seating arrangements, specifically, the first row in front of the viewing mirror tends to be reserved for the "regulars," those with specified responsibility and/or constant attendance. Rows farther back are left for those coming only briefly, such as medical students on rotation, and those stopping in for only part of the session or leaving early, that is, not "full participants."

A unique expression of group process in the observing group could be seen in the early stages of the couples group when the 
cotherapist couple clashed over treatment philosophy and their working relationship. In this instance, the female partner felt that the male was dominating and operating in a condescending fashion toward her. This conflict was resolved by the female partner, who chose to leave the group and be replaced. Of significance here is the response of the observing group during this period. Although some feared there would be a great fight, spilling over from the therapists' relationship into the couples group itself, this did not occur. The fight, instead, showed up within the observing group, with a male/female split initially taking place among the observers. Heated discussion took place among the observers as the cotherapy relationship rapidly deteriorated. With each sign of difficulty, the observers took sides. Several of the joint discussions with both therapists and observers after the therapy sessions were preoccupied with this issue. As this continued, the observers eventually resolved among themselves to say nothing rather than take sides in the discussion section, and to let the therapist couple settle the dispute. Their hope was to protect the couples group by not prolonging the agony. The "regulars" seemed to lead this movement, commenting and anguishing out loud over the disruption caused by the crumbling cotherapist relationship, and then holding separate discussions among the observers about what their response to the crisis should be. Following the observing group's decision to stay out of the problem, postsession meetings took on a subdued air, with observers holding back to allow faster resolution and to protect themselves. A separate and distinct group formation had taken place. Apparently it worked, as this position did not add fuel to the fire and allowed the cotherapists to settle their situation. Given the intensity of the observers' involvement in the cotherapy conflict, the relative lack of involvement of the patient couples group seemed remarkable. No couple used the splitting up of the cotherapists' relationship as a resistance to change or an excuse to leave the group.

It is interesting to note the difference in observation of the same event from the other side of the mirror. As observed from the teaching therapist's side of the mirror, the observing group became intensely identified with one or the other of the cotherapists, displaying both personal problems and transferences. The observing group seemed more disturbed by the events than did the treatment group. Careful observation of the treatment group, both during the difficulties that surfaced in the first hours and also after the cotherapist left and was replaced by a new cotherapist, showed surprisingly little reaction to the loss. There was only minimal interference with group process. The clearest explanation seems to be that this event occurred so early in the life of the therapy group that the members had little opportunity to 
form relationships with the cotherapist. In contrast, the disturbance within the observing group was intense and continued to reverberate through future group meetings. The traumatic experiences of trainees with personal knowledge of power struggles with senior staff held meanings for the observing group with which the treatment group did not identify. For the teaching therapist, it was once more a lesson emphasizing the necessity for very carefully structured communication between cotherapists before undertaking a cotherapy relationship under these circumstances. Krasner, et al., make the same point in reference to the observer situation: "With more structure, and thus less ambiguity, there will be less intense transtransference-countertransference reactions, and therefore less interference with the learning process." Also relevant here is the importance of a suitable matchup between cotherapists. Recent literature highlights the critical importance of basic trust in forming viable cotherapy relationships (Weinstein, 1971). Such trust provides the basis for cooperative effort and acceptance of the differences between therapists so that the relationship can become a "model of respected differentness in which co-therapists remain supportive but separate" (Fairhood, 1975).

A less striking demonstration of group process-but the area in which the most educative benefit could be derived-was the response of the observing group as a whole to individuals, particular couples in the group, the therapists' handling of material and interpretations, and the specific process of the couples group. As individuals in the group would reach points of resistance to change, or fail to respond to their partners' painful revelations of themselves, participants in the observing group would root and call out encouragement or express their dismay and anguish. When couples would either change, remain the same, or abandon the group, there were expressions of concern, dismay, joy, and deeply touching feelings. A particular couple, having joined the group in a state of murderous crisis, were later able to reach the point where the cold, withdrawn man could break the walls and reach out to his wife, and there wasn't an untouched eye or heart in the entire observing group.

This impact of the highly charged process of group therapy-indepth on the observers has been a constant stimulus for them to experience more of themselves and their own marriages. In many small ways, the process of the observers seeing themselves in the patients was evident in the observing group. In one such instance, when a wife was complaining about her husband not calling to let her know where he was, one observer jumped up, ran over to the phone and telephoned his wife-something he had forgotten to do. Many observers, moreover, have found themselves picking up reactions of their own 
and others that are not recognized, acknowledged, or utilized by the teaching therapist and utilizing them for their own work within themselves. Furthermore, observers often help each other by discussing their reactions in the absence of the teacher and sometimes find observations of their peer group to be better tolerated and more therapeutically utilizable than those of the teacher. Avoidance of the father-figure confrontation is less painful than facing him through the sibling united front. However, an equally important process is at work. The observing group members need to maintain a relation to the senior therapist that is respected but separate. The danger of fusion needs to be avoided. At times, the junior cotherapist has also found it helpful to utilize the observing group in this way. In these instances, the observation experience serves for some as a kind of indirect psychotherapy, even without the presence of a therapeutic contract in the group. In addition, the observers' oscillating and partial identifications with both therapists and patients often highlight alternative technical approaches to material presented in the group and stimulate learning that results in acquisition of therapeutic skills.

\section{The View As Seen by Newcomers to the Observing Group}

The new members who join the ongoing observing group have little feeling at first "of belonging in the true sense of the word." They recognize the existence of the core group, which has been together for a while, and experience a highly reinforced group norm to keep the status quo. The seating arrangement is such that certain members always sit in the front row, almost in the exact order each week. If a seat is unoccupied, it is "saved" for the core member. The core group are those who make commitments in terms of (a) exposing their thoughts and reactions in order to learn and to contribute to the learning of others; (b) showing up regularly or being accountable for absence; (c) sharing their own work process, thus risking criticism; (d) demonstrating skills and knowledge in marital and group therapy; and (e) participating in administrative tasks. The core group develops intimate bonds, despite the relative absence of overt verbal communication by (a) sharing moments of intense emotion observed through the mirror; (b) experiencing close physical proximities by squeezing together in front of the mirror and seeing each other's faces reflected in the glass; and (c) helping each other out by saving a seat, filling in the last week's process notes, repeating a poorly heard comment, sharing insights about the techniques of the cotherapists, and sharing lunches. 
It seems that an unspoken initiation process exists before the newcomer is accepted into the core group. In observing the therapy group, the newcomer feels as if he or she is being bombarded simultaneously with an enormous amount of stimuli and is trying frantically to select out that which is important. It feels overwhelming to try to watch the therapeutic process and also to try to determine the dynamics of each individual and the relationship to the respective mate. Transference reactions abound. In the discussion session, the newcomer again feels the core group's control of questions and discussion, and fears asking basic questions that would not be astute or perceptive. As time passes, the newcomers become more comfortable within the observing group and also in viewing the therapy group. They develop the freedom to watch the therapeutic process without being caught up in the emotionality of the therapeutic group or of the observing group. This can occur whether the newcomer feels accepted and becomes a part of the core group or continues to feel excluded. One newcomer who desired more cohesiveness in the group observed that therapists-in-training are still building their personal understanding of human interaction, their personal confidence, and proficiency. This leads to a de facto defensiveness and social distance. Cohesiveness suffers for personal comfort-yet the distance creates discomfort in its own right. It is interesting to observe how this dilemma, given sufficient time, can usually be overcome by the work of group process. In time, most observers feel freer to be themselves, overcome most of their fears of the self-exposure necessary in order to learn, and develop emotional ties to the other group members that enhance and support the learning situation.

\section{CONCLUSION}

This paper attempts to make a contribution to an area of the literature on group therapy about which very little has been published-the effects of the therapy group upon the observing group and the dynamics of the observing group as an entity in itself. Although work on which this paper is based took place in training institutions where education is the primary function, it is important to emphasize that education and personal change are interrelated. Psychotherapeutic activity takes place spontaneously with the observers and needs to be constructively utilized. This wealth of process and reaction is an untapped training opportunity for the observing group. The challenge of method, personal reactions, and group process responses are all opportunities for its members to both learn more as therapists and mature as individuals. At this juncture, we are trying to establish ways of 
furthering therapist education and growth by means of the observing group process.

\section{REFERENCES}

Berne, E. Principles of Group Treatment. New York: Oxford University Press, 1966.

Bloom, V., \& Dobie, S. I. The effect of observers on the process of group therapy. The International Journal of Group Psychotherapy, 1969, 19, 79-87.

Ekstein, R., \& Wallerstein, R. S. The Teaching and Learning of Psychotherapy, (2nd Ed.). New York: International Universities Press, 1972.

Fairhood, L. Choosing a partner for co-therapy. Perspectives in Psychiatric Care, 1975, 13(4), 177-179.

Goforth, E., Mowatt, M., \& Clarke, N. Effect of the presence of an observer and a hidden observer on the defensive patterns of an ongoing group. The International Journal of Group Psychotherapy, 1966, (16), 338-342.

Kadushin, A. An experience in tape recording interviews; report of an adoptive follow-up study. Journal of Jewish Communical Service, Summer 1967, 43(4), 327-334.

Krasner, J., Feldman, B., Liff, Z., Mermelstein, I., Aronson, M. L. \& Guttmann, O. Observing the observers. International Journal of Group Psychotherapy, 1964, 14, 214-217.

Kritzer, H., \& Phillips, C. A. Observing group psychotherapy-an affective learning experience. American Journal of Psychotherapy, 1966, 20, 471-476.

Martin, P. A. A Marital Therapy Manual. New York: Brunner/Mazel, 1976.

Powdermaker, F., \& Frank, J. Group Psychotherapy. Cambridge: Harvard University Press, 1953.

Rice, D. G., Fey, W. F., \& Kepecs, J. G. Therapist experience and "style" in co-therapy. In A. S. Gurman \& D. G. Rice (Eds.), Couples in conflict. New York: Aronson, 1975, 151-161.

Rice, J. K., \& Rice, D. G. Status and sex role issues in co-therapy. A. S. Gurman \& D. G. Rice, (Eds.), Couples in conflict. New York, Aronson, 1975, 145-150.

Weinstein, I. Guidelines on the choice of a co-therapist. Psychotherapy: Theory, Research and Practice, 1971, 8, 301-303.

Wolman, R. N. Through the one-way mirror: An analysis of the dynamics in the observation of psychotherapy. Psychotherapy: Theory, Research and Practice, 1970, 7, 108-110. 